\title{
ENABLERS AND INHIBITORS OF E-TAX System Use:The Perspective of DUAL-FACTOR CONCEPTS
}

\author{
Md. Faridur Rahman ${ }^{1}$, Md. Shamim Talukder ${ }^{2}$ and Dr. Yang Lanrong ${ }^{1}$ \\ ${ }^{1}$ College of Public Administration, Huazhong University of Science and Technology, \\ Wuhan, P. R. of China \\ ${ }^{2}$ Department of Management, School of Business and Economics, North South \\ University, Bangladesh
}

\begin{abstract}
The aim of this study is to investigate the acceptance and rejection behavior of electronic tax system at the same time. This study applied a conceptual framework focused on the dual-factor concepts of "enablers" and "inhibitors" to illustrate users' desire to exercise the e-tax system. In the dual model the Theory of Consumption Value (TCV) and Status Quo Bias (SQB) have been used to describe the reason behind consumers' accepting or rejecting the e-tax system through perceived enablers and deliberate inhibitors. A survey has been conducted in Bangladesh to collect data from 422 taxpayers, and the structural equation model was used to validate the proposed model. We find that functional value, social value, and emotional value are seen to have positive and direct impacts on the user's preference to use the e-tax system, while user's resistance to use adversely impacts the use of the e-tax system. The results also signify that the user's resistance to using the e-tax is due to switching costs, inertia, and perceived risk. Several suggestions are provided for the practitioners to implement the e-tax system successfully by eliminating resistance factors.
\end{abstract}

\section{KEYWORDS}

Dual-factor model; E-government; e-tax filing; theory of consumption value; status quo bias; useintention.

\section{INTRODUCTION}

The advent of numerous innovations encouraged the growth of information and communication technologies (ICTs) in several countries and transformed how government services are provided to people. By exploiting ICT developments, the conventional environment of government services has changed to improve people's welfare through sustainable development $[1,2]$. ICT is commonly used in all aspects of society and plays an increasingly important role in interactions between governments and citizens. E-Government is a digital form of government agencies, where maximum transactions related to the administration are performed electronically to boost government efficiency, enhance communication, and speed up the delivery of services to people $[3,4]$. As a result, several initiatives have been performed through e-government to develop systems focused on public needs and make government services more accessible to people [5].

Among the numerous online services that the government offers, e-tax is possibly among the most commencing and widely used e-government platforms [6]. The e-tax system is an essential online service through which the citizens can record their income tax returns safely and comfortably [7]. The key benefit of the e-tax system is that it incorporates tax preparation, filing of online tax returns, and online tax payment facilities in one system [8]. This method is 
incredibly beneficial to the governments as it eliminates a lot of errors made by the taxpayers during manual filings. Also, it enables to restrain tax evasion by matching data. Data warehouses set up with the electronic tax filings allow the tax inspectors in examining documents accurately and enable the policymakers to create fair and equitable, and appropriate tax policies [2]. The IT-led e-tax filing system is gaining popularity to assure accessibility and distribution of government information and services to residents, business partners, employees, and other agencies and entities $[9,10]$.

The success of e-government depends on whether governments are able to attract citizens to accept and use online public services [11]. Studies so far have shown that e-government initiatives have failed involve citizens, especially in developing countries. Creating conditions for access and use does not guarantee acceptance of e-services [12, 13]. When an innovative technology is introduced, the users can choose to accept or reject it based on assessing the new systems' changes $[14,15]$. Traditionally, continuous failures have affected the implementation of information technology, and user resistance has been repeatedly described as the main reason behind it $[5,16]$. Apparently, the users get habituated to the resources they have used for a long time and neglect the necessity for modern and upgraded technologies [17]. Cenfetelli [18] argued that current theories of IS use, as in TAM [19], have concentrated just about entirely on the positive (enabling) perceptions of IS use. However, overlooking negative (inhibiting) impressions may impede IS use.

As a result of a comprehensive emphasis on enablers and the avoidance of inhibitors, while our present IT adoption models give fairly good explications for adoption behaviors, they fail to provide an apparent reason for non-adoption or rejection behaviors [20, 21]. Consequently, neither acceptance nor potential usage can happen until the factors that hinder the new systems' usage are addressed [21, 22]. More comprehensive and extended models are therefore required to clarify the successful adoption and usage of e-tax systems [18, 21, 23]. In order to fill these gaps, we suggest that the Cenfetelli [18] dual-factor model can provide adequate justification for the acceptance and exercise of the e-tax system. The dual-factor model offers a plain sailing theoretical bridge that puts the e-tax enablers and barriers into an integrative framework [21, 24]. Explicitly, in the dual-factor model, this study proposed the Theory of Consumption Value (TCV) [25] to identify several enablers (functional value, social value, emotional value, and epistemic value) that facilitate the e-tax system adaption while the status quo bias (SQB) was used as inhibitors (switching costs, inertia, perceived risk, and anxiety) to identify the effect of resistance on e-tax system adoption. This study's results are effective while planning compatible strategies to inspire more significant usage of the e-tax system in the background of Bangladesh in particular and the developing world in general.

\section{Current State of Research}

Till date, research on e-tax systems adoption and use have been conducted widely and has been common in the literature $[6,26,27]$. In this regards, various theories such as the ECM, the DOI, the TAM, the TPB, the theory of reasoned action (TRA), the IS success model, the UTAUT, and the SCT have been utilized, sometimes in combinations with one another, to study e-filing usage [9, 28-32]. These studies have mainly focused on "enablers" or positive factors that drive future use [15, 18, 33]. Such enablers include perceived usefulness, perceived ease of use, social influence, and perceived compatibility [9, 27, 30, 34].

Nevertheless many researchers argued that when deciding to adopt new IT products, an individual user can be influenced by two main factors: accepting innovation and maintaining existing habits which induce user resistance [35, 36]. Likewise, Venkatesh and Brown [37] 
assert that, in the non-adoption of a new technology, are more important than those factors that are influential in the adoption decision. The consequence of sole focus on enablers and exclusion of inhibitors is that while our current IT adoption models provide reasonably good explanations of adoption behaviors, they cannot adequately explain non-adoption or rejection behaviors [38]. Consequently, neither acceptance nor future use will occur unless the factors that inhibit the use of new systems are overcome [21, 39]. Therefore, it is necessary to investigate positive and negative factors combinedly. Therefore, more complete and extended models are necessary to explain effective e-tax system adoption and use from enablers and inhibitors perspectives [18, 21, $40,41]$. Therefore, research on technology acceptance and resistance behavior need to investigate simultaneously. The dual factor model offers a straight forward theoretical bridge that brings together facilitators, inhibitors to use e-tax system in an integrated model $[21,36]$.

\section{The Oretical Framework}

\subsection{The Enabler-Inhibitor perspective}

Cenfetelli [18] dual-factor theory implies that, while a new idea, process, and action are confronted, people establish the intention to embrace or oppose this creativity by reacting with two separate stimuli sets. Various determinants associated with each set of motives lead to promoting or hindering the desire for pursuing an innovation $[15,35]$. The enablers promote and impede project adoption, whereas the inhibitors anticipate rejection that prevents use when present but do not inherently support use in their absence. Inhibitors and enablers are different, autonomous mechanisms that can coexist and possess separate histories and implications [18].

Cenfetelli [18] dual-factor theory has been used as a means of determining when users plan to use e-government services. Cenfetelli [18] argued that where the enablers can best predict IS acceptance, the inhibitors can forecast IS rejection very well. The enablers are the outer assumptions regarding the characteristics of an IS that either promote or discourage use, depending on the importance of the IS. Whereas the inhibitors are hygienic variables that prohibit IS use while being present but generally reject to support use when absent. This asymmetric effect means that the inhibitors are not precisely inverse of the enablers but are subjectively unique structures that are separate but still exist together with the enablers.

Additionally, inhibiting beliefs can be differentiated from enabling views through facing different experiences and subsequent consequences. In the background of e-government services, researchers have empirically shown that a dual model regarding primary behavioral inhibitors and enablers is a successful way to understanding citizens' acceptance of ICT networks [17, 21, 35]. Consequently, Cenfetelli's dual-factor IS usage model offers a theoretical bridge connecting acceptance of IS and resistance in the integrated framework that was applied in this research.

\subsubsection{Enablers: Theory of Consumption Value (TCV)}

The Theory Consumption Value developed by Sheth, et al. [25] consists of a conceptual framework for studying the enabling factors determining the e-tax systems' adoption. TCV, a theory that describes the reason behind the consumers' behaving in a specific way while making decisions between different products or services. This theory states that behaviors, as in usage situations, depend on consumer principles. The principles are basically the intrinsic and extrinsic factors and motivations influencing choices. The consumption values are of five types: functional value, social value, emotional value, epistemic value, and conditional value. All these are equally exclusive and relate independently to actions. In other terms, customer behavior results from the customer's interpretation of certain values related to a specific product or service [25]. In several previous research articles, TCV has been used to describe technology-related decisions and has 
repeatedly maintained strong predictive validity of the technology [42,43] and suggested as an improved model for the IT adoption model over the excessively described TAM model [44, 45]. However, just like other studies, only four important consumption values, namely functional value, social value, emotional value, and epistemic value, are selected as enablers in the dualfactor model to fit into the context of the e-tax system. Hypotheses on these variables indicate constructive relationships to use the e-tax system.

\subsubsection{Inhibitors: Status Quo Bias (SQB)}

The status quo bias viewpoint suggests that preserving the status quo is a bias of decisionmakers. The tendency is to remain idle or retain one's present or past decisions, which signifies why people make decisions in disproportionate numbers to resume the old action instead of going for new ones [46]. Samuelson and Zeckhauser [46] classify the status quo bias viewpoint into three major classes: rational decision-making, psychological commitment, and cognitive misperceptions. Fair decision-making alludes to evaluating the potential costs and advantages of change before deciding on a new move. Higher costs than rewards contribute to inequality in the status quo. There are two forms of costs considering a rational decision-making point of view: uncertainty and transition cost [16]. Uncertainty costs constitute negative psychological reactions to uncertainty associated with new situations and biases subjects toward the status quo [47]. Transition costs include temporary expenditures and inevitable losses the transition is linked with. As losses and costs rise, people become resistant to adjust as they fail to minimize losses [16].

Rational decision-making alone will not clearly describe the status quo bias since it can also be the product of cognitive misperception that arise from risk aversion [46]. As per cognitive misperceptions, people appear to evaluate dormant losses as greater than latent gains in deciding if they should step away from the status quo [48]. From a cognitive misperceptions point of view, persistence allows the status quo to adapt to a new method despite having better options or benefits to change [35]. The most recent explanatory group of the status quo bias applies to psychological dedication. The three major determinants that lead to psychological commitment are sunk costs, social expectations, and attempts to sense in charge [46]. This desire can lead toa bias in the status quo as people do not want their power to be lost while transitioning to a new system or an unfamiliar working approach. Numerous IT adoption studies have validated the SQB perspective and recommended explanations for user resistance [15, 35, 39]. In order to enhance understanding of users' resistance behavior, we incorporate one additional user perceptions that is anxiety into the original SQB as inhibitor. The technology adoption literature has identified anxiety as user perception to play a salient role to discuss why individuals prefer to stay within an incumbent system [15]. In this analysis, SQB (switching costs, inertia, and perceived risk) and technology anxiety are used as a basis for understanding user resistance.

\subsection{Research model and hypotheses development}

On the basis of the previous discussion, we use the dual-factor model of IS usage asan essential theoretical foundation in the usage literature of IS. To justify the adoption and resistance behavior of individuals and to identify factors that influence their behavior, this factor integrates and adds to relevant concepts from the TCV and SQB theory. Figure 1 shows the theoretical framework of the study integrating different enablers and inhibitors. In the enabling perceptions scenario, it is recommended that citizens' choice of using the etax system depends on four value perceptions of IS usage: functional value, social value, emotional value, and epistemic value. Likewise, in terms of inhibiting perceptions, switching 
International Journal of Managing Public Sector Information and Communication Technologies (IJMPICT)

Vol. 12, No.1, March 2021

costs, inertia, perceived risk and anxiety propose as user resistance antecedents. More justification for including these constructs and details of all hypotheses are explained in the following section.

\subsubsection{Functional value}

Functional value can be characterized as value arising from the fulfilment of consumers useful, valuable, and functional purposes of goods and services. It is critical to the performance, reliability, durability, and value of the product and service [25, 49]. When it comes to the e-tax system, the ability to provide easy access to the system, one-stop service, accurate and reliable information, and cost-effective service add value to its users. In the case of IS and online service, functional value has analytically explained to be positively impactful in users' behavioral intentions regarding information systems usage [9, 42, 50-52]. Hence, we argue that their perceived functional value influences the user's e-tax system adoption intention. Therefore, the study formulates the following hypothesis:

H1. Functional value positively affects the behavioral intention to use the e-tax system.

\subsubsection{Social Value}

Social value includes social acceptance and self-image enhancement among people [52, 53]. The purchasing and use of products and services is a way by which a person can convey a social self-image to everyone else [43]. In the current scenario, it is quite evident that the e-tax system is considered an advanced technology, and that too much focus is being paid to it. The e-tax system offers social value by allowing the consumer to transmit an image to someone in a manner equivalent to many fashion products [54]. In the information systems' context, several previous varieties of studies have well shown that social value can possess a great impact on the intention behavior of using IS artifacts or e-tax systems [55-57]. Therefore, it is our claim that the e-tax system usage is now considered a trendy and modern system, so that people using this platform can promote self-image. Accordingly, we propose the following hypothesis:

H2. Social value positively affects the behavioral intention to use the e-tax system.

\subsubsection{Emotional Value}

Sheth et al. (1991b) defined emotional values as tangible usefulness derived from the ability of the substitute to arouse emotions or affective responses. It mentions the capacity of products and services in activating affections or emotions. The emotional meaning varies based on personal perceptions and can be positive, negative, or neutral on the basis of various usage conditions [45, 58]. In terms of the e-tax system, there is a feeling that can be stimulated when users pay their tax electronically, avoiding attending the tax department, working for a long line, or meeting sluggish income tax officers. Studies have shown that emotional value is significant in IT services usage [59], in mobile apps usage [43] and in internet banking services usage [44]. We, therefore, conclude that the higher the emotional attachment, the more the consumer would be involved in using the service. Thus, based on the finding of earlier studies, we put forward the following hypothesis:

H3: Emotional value positively affects the behavioral intention to use the e-tax system.

\subsubsection{Epistemic Value}

Epistemic value generates if the product or service is interesting, innovative, and fulfills the 
International Journal of Managing Public Sector Information and Communication Technologies (IJMPICT) Vol. 12, No.1, March 2021

demand for learning [25]. Tang and Forster [60] describe epistemic values as individuals' variation-seeking and novelty-seeking attitudes. In our study background, the e-tax system is a modern and exciting technology that is likely to stimulate taxpayers' interest to try out a modern electronic program. Therefore, we claim that taxpayers would demonstrate their desire to use the e-tax system from a knowledge-seeking point of view. Hence, we propose the following hypothesis:

H4. Epistemic value positively affects the behavioral intention to use the e-tax system.

\subsubsection{Switching costs}

Burnham, et al. [61] described the switching costs as the one-time costs that the customers incur while switching from one supplier to the other. Switching costs are the assessment of time, resources, and effort by consumers that results when the service providers are changed [62]. In our study background, the e-tax system is a relatively new concept in Bangladesh, and users are not well acquainted with the new system; they may anticipate effort and time to know about new systems, which may lead to inconsistencies and adverse responses contributing to user resistance. Therefore, the introduction of a new IS can entail changing the way where itoperates, which undermine changes already made and hence lead to user resistance. In the literary works, switching costs have been widely studied as determinants that affect IT resistance to change [16, 63]. Thereby, we claim that moving to the e-tax system entails several social and cognitive costs and that certain costs minimize switching rates. Hence, we hypothesize that:

H5: Switching costs positively affect user resistance to use the e-tax system.

\subsubsection{Inertia}

Inertia defines the customer or user behavior pattern of relying on what was previously selected, what is the existing state of things [46]. Inertia is regarded as an implicit human emotion that recurrent usage or purchase is conducted unconsciously, without worrying or considering the goods or services' negative attitudes [64]. In the case of our study, as consumers are attached to the conventional paper-based tax service, they are hesitant to take over an online tax service even though there are better options and incentives to adjust. According to many precedent research in the IS service sense, inertia positively and strongly impacts consumer resistance toIT services' adoption [35, 64]. Therefore, we claim that higher resistance to the use of the e-tax system results from higher inertia. Consequently, we propose the following hypothesis:

H8. Inertia positively affects user resistance to use the e-tax system.

\subsubsection{Perceived risk}

Perceived risk is the insecurity that impacts people's actions on online transactions [65]. Huang, et al. [66] observed that perceived risk possessed a strong negative effect on the electronic tax filing and payment system usage in Taiwan. Perceived risk is a key element in the early stages of the adoption of the citizens' e-tax system because, at this point, customers are not very confident and knowledgeable of government services. Thus, it is necessary to recognize the risk involved in electronic tax returns and the ability of them to keep faith in e-tax websites to gather and give confidential information. Digital taxpayers might have questions regarding the privacy suspicions and costs involved because of the security deficiencies of their sensitive details. Literature points out the inverse correlation between the perceived risk of users in the e-tax system and the ability of them to be used to with this type of electronic services [2,9]. Therefore, we argue that perceived risk raises the resistance of users to exercise the e-tax systembecause of 
International Journal of Managing Public Sector Information and Communication Technologies (IJMPICT) Vol. 12, No.1, March 2021

fears of adverse repercussions such as loss of personal details and loss of money. Hence, we suggest the following hypothesis:

H7. Perceived risk positively affects user resistance to use the e-tax system.

\subsubsection{Technology anxiety}

Technology anxiety (also known as computer anxiety) comprises negative emotions, apprehension, and fear associated with technology applications as in computer and mobile technologies [67]. In the information technology adoption context, users with technology anxiety are suspicious of losing personal data, making mistakes in data input, damaging equipment, or perceived incapability may generate adverse feelings, which may lead to a negative manner towards technology. Tsai, et al. [15] have found that technology anxiety causes a substantial negative impact on users' mobile health services usage considerations. From the above discussion, we argue that users with technology anxiety will resist using the e-tax system. Thus, we propose the following hypothesis:

H8: Technology anxiety positively affects user resistance to use the e-tax system.

\subsubsection{Resistance to use}

User resistance in IS literature has been framed as a severe effect or resistance of users to perceived changes linked to the current implementation of IS [16]. Since the new ISs' introduction means switching from one method to the other, resistance expresses itself as a reluctance to switch the already used technology with another [48]. Marakas and Hornik [68] describe the actions of resistance as a reaction to threats related to new technology. Resistance isa significant obstacle to implementing the e-government services [21, 69]. In our study context, taxpayers are accustomed to and familiar with the traditional paper-based tax service for a long time, and they are also anxious about the security and privacy of the government's new online tax submission system; consequently, they will resist adopting the new e-tax system. Hence, we argue that the user's resistance decreases the adoption intention of the e-tax system. Therefore, we recommend the following hypothesis:

H9. User's resistance to use negatively affects user intention to adopt the e-tax system. 

Enablers

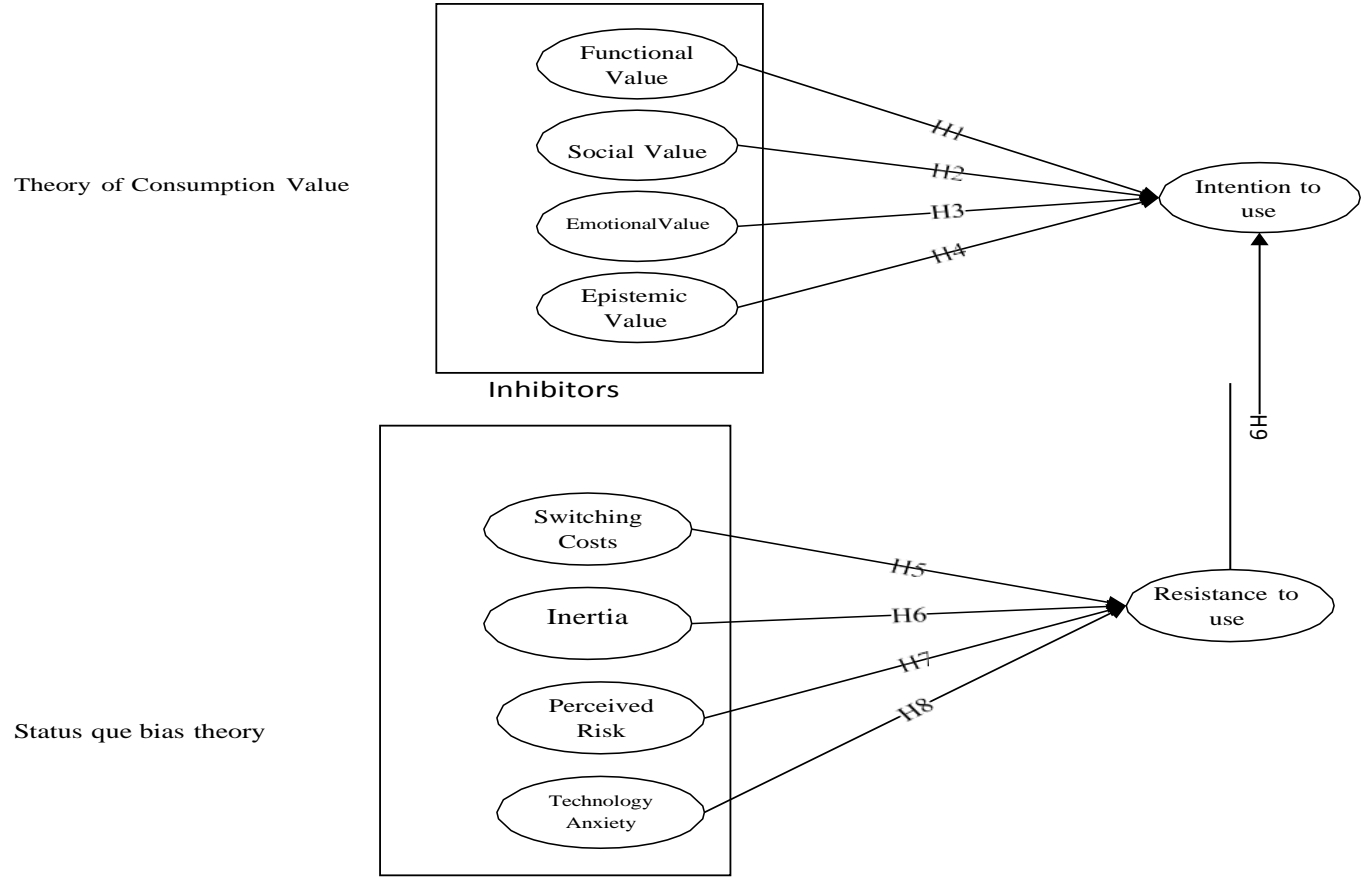

Figure 1. Research Model

\section{RESEARCH METHODOLOGY}

\subsection{Study context}

This study has been conducted in Bangladesh. The government of Bangladesh has been leveraging the advantages of e-government through several applications. Among the egovernment services in Bangladesh, the most well-known one is the e-tax service, also known as 'e-filing'. The e-tax service was introduced by the National Board of Revenue (NBR), Bangladesh in November 2016 with a cost of $\$ 7.5$ million, aim to enhance tax collection, increase the efficiency of tax administration, provide better service and reduce the cost for taxpayers and tax collecting authority. However, the newly installed e-tax system failed to attract taxpayers, and most of the taxpayers still prefer to queue at tax offices for manual submissions. Out of 2.2 million tax payers only 7,209 $(0.3 \%)$ tax payers submitted their returns online in the fiscal year 2019-2020 [70, 71]. Therefore, it is needed to understand the cause of this low acceptance.

\subsection{Measure of Constructs}

More or less, every item has been reconciled from reputed literature to confirm the scale's content reliability (see Appendix A). All the latent constructs in the questionnaire got ratings on a 5-point Likert scale anchored from "strongly disagree" to "strongly agree." The 5 point Likert scale, a highly accepted method used in a wide-ranging empirical research where no standard estimate exists to quantify conceptions like capabilities and resources, will be used for all constructs and items [72]. The survey was pre-examined, and prior to the final survey, a pilot study was conducted. Two IS academic scholars ran the pre-test to assess its accuracy, order, and accuracy with the measurement objects. Besides, a small pilot study with 20 taxpayers was conducted in Dhaka, Bangladesh. Taking into account of various comments from experts and respondents' 
International Journal of Managing Public Sector Information and Communication Technologies (IJMPICT) Vol. 12, No.1, March 2021

feedback from pilot test, we made minor changes regarding wording and sequence in the questionnaire and it was ready for the study.

\subsection{Data Collection and the Sample}

The individual taxpayers from five tax zones of Bangladesh, named Dhaka, Chittagong, Rajshahi, Khulna, and Gazipur, were the study population. The number of taxpayers and representation was taken into consideration for the convenience of sampling procedures. Both the users and non-users of electronic tax filing were used in the study as sample. A quantitative approach is used to collect data for the study. For the primary data collection method, an online questionnaire was designed. Firstly, because of the ongoing pandemic situation, it is not possible to survey through a printed questionnaire. Secondly, the taxpayers are well-educated government and non-government officials and self-employed persons who are regular internet users and more used to online services. Thirdly, according to studies, an online survey is more convenient than physical surveys [73-76]. Finally, an online survey questionnaire can be reached out to more geographical locations more time and cost-efficiently. Besides, an online survey assures the least interviewer biases of any kind as the respondents know that their answers will not be traced back to them once the submission is made. [77].

The questionnaire was designed with two sections. Few demographic information regarding age, gender, and tax systems usage knowledge were required in the first section. And questions regarding constructs of the research model were asked in the second section. Our questionnaire link was sent through e-mail and social networking sites (i.e., Facebook). 475 respondents in total participated in the survey, and after eliminating the inappropriate and blank responses, 422 appropriate responses were gathered (89\% response rate). The participants' demographic information demonstrated in Appendix B signifies that among 422 participants, 61 percent are males, and 39 percent are females. In the age distribution breakdown, the majority group belongs to 30-39 years (43 percent). Besides, the dominant portion of the participants (55 percent) have the qualification of masters or higher education. Lastly, most of the respondents (60 percent) have 2 - 4 years of e-government service user experience.

\subsection{Statistical Analysis}

Structural equation modeling (SEM) was used to evaluate the causal relationship between the variables in the measurement model and the structural model [78]. SEM is very versatile sinceit interacts with not only a single simple or multiple linear regression, but also with a series of regression equations. The rationale for using SEM rather than ordinary regression analysis is that it is suitable for analyzing equations at the same time [79]. The same variable may be a factor in one equation and a parameter in another equation. In particular, the most influential function concerns its capacity to deal with latent variables, i.e. non-observable variables, such astrue-score variables or factors influencing the measured variables [80]. Commercial program SmartPLS 3.2 was used for data analysis in this study.

\section{Result}

\subsection{Measurement Model}

With the measurement model part, it was considered a variance of internal reliability, convergent validity and discriminant validity. Internal reliability was considered a variance of Cronbach's alpha and composite reliability (CR) should be up over 0.7 of variance [81]. The result of this study found variance of Cronbach's alpha and composite reliability (CR) between 0.732 to 0.871 
International Journal of Managing Public Sector Information and Communication Technologies (IJMPICT) Vol. 12, No.1, March 2021

and 0.849 to 0.911 that every variance passed indicating criteria of internal reliability. Convergent validity was considered with AVE and Loading variances that should be up over or equaling at 0.5 [82]. From Table 1 and Appendix A, the result of this study found AVE range between 0.643 to 0.745 and items loading ranged from 0.703 to 0.925 indicate that data fulfill the convergent validity criteria. Lastly, discriminant validity was considered Square of AVE was larger than its correlation with other factors [83]. Every variance passed indicating criteria presented in Table 2. Therefore, all the criteria for internal reliability, convergent validity and discriminant validity were being satisfied in this study.

Table 1. Measurement model

\begin{tabular}{|l|l|l|l|}
\hline \multicolumn{1}{|c|}{ Constructs } & Cronbach's Alpha & Composite Reliability & AVE \\
\hline Behavioral Intention to use & 0.815 & 0.889 & 0.729 \\
\hline Epistemic Value & 0.735 & 0.849 & 0.653 \\
\hline Emotional Value & 0.820 & 0.893 & 0.737 \\
\hline Functional Value & 0.870 & 0.911 & 0.720 \\
\hline Inertia & 0.761 & 0.863 & 0.679 \\
\hline Resistance to use & 0.809 & 0.875 & 0.636 \\
\hline Switching costs & 0.871 & 0.910 & 0.772 \\
\hline Social Value & 0.732 & 0.844 & 0.643 \\
\hline Technology Anxiety & 0.844 & 0.897 & 0.745 \\
\hline Perceived risk & 0.826 & 0.896 & 0.742 \\
\hline
\end{tabular}

Note: AVE = Average Variance Extracted

Table 2. Correlation matrix and square of the average variance extracted

\begin{tabular}{|l|l|l|l|l|l|l|l|l|l|l|l|}
\hline & BI & EPV & EV & FV & INT & RC & SC & SV & & TA & PR \\
\hline BI & $\mathbf{0 . 8 5 4}$ & & & & & & & & & & \\
\hline EPV & 0.519 & $\mathbf{0 . 8 0 8}$ & & & & & & & & & \\
\hline EV & 0.342 & 0.156 & $\mathbf{0 . 8 5 8}$ & & & & & & & & \\
\hline FV & 0.603 & 0.622 & 0.197 & $\mathbf{0 . 8 4 9}$ & & & & & & & \\
\hline INT & 0.687 & 0.57 & 0.252 & 0.64 & $\mathbf{0 . 8 2 4}$ & & & & & & \\
\hline RC & 0.624 & 0.564 & 0.235 & 0.639 & 0.715 & $\mathbf{0 . 7 9 8}$ & & & & & \\
\hline SC & 0.032 & 0.009 & 0.339 & -0.023 & -0.017 & 0.043 & $\mathbf{0 . 8 7 8}$ & & & & \\
\hline SV & 0.608 & 0.463 & 0.169 & 0.503 & 0.556 & 0.478 & -0.079 & $\mathbf{0 . 8 0 2}$ & & & \\
\hline TA & 0.066 & 0.06 & 0.26 & -0.034 & 0.053 & 0.099 & 0.227 & 0.054 & & $\mathbf{0 . 8 6 3}$ & \\
\hline PR & 0.519 & 0.49 & 0.219 & 0.548 & 0.659 & 0.583 & -0.033 & 0.434 & & 0.052 & $\mathbf{0 . 8 6 1}$ \\
\hline
\end{tabular}

$\mathrm{BI}=$ Behavioral Intention to use, $\mathrm{EPV}=$ Epistemic Value, $\mathrm{EV}=$ Emotional Value, FV = Functional Value, INT = Inertia, $\mathrm{RC}=$ Resistance to use, $\mathrm{SC}=$ Switching costs, $\mathrm{SV}=$ Social Value, $\mathrm{TA}=$ Technology Anxiety, $\mathrm{PR}=$ Perceived risk

\subsection{The Structural model}

SmartPLS 3.2.8, a widely accepted statistical software, was utilized to inspect the structural path coefficients and the R-square values of endogenous constructs that tested and validated the explanatory and relevant predictive power of the model. Furthermore, the bootstrapping method, which is relatively new to the field of the statistic, was also applied for testing the hypotheses [79]. These values were extracted by running with 5000 samples and no sign changes in the bootstrapping technique [84]. In this stage, the relationship between the dependent and independent variables was examined by path coefficient $(\beta)$ and t-statistics at a level of significance of $0.05(\mathrm{p}<0.05)$, as referred to figure 2. Specifically, the result indicates that $\mathrm{H} 1$, 
International Journal of Managing Public Sector Information and Communication Technologies (IJMPICT) Vol. 12, No.1, March 2021

$\mathrm{H} 2, \mathrm{H} 3, \mathrm{H} 5, \mathrm{H} 6, \mathrm{H} 7$, and H9 were significantly supported while H4 and H8 were not statistically significant towards intention to use e-tax system (details in table 3 ).

Table 3. Path coefficients and their significance

\begin{tabular}{|l|l|l|l|l|}
\hline No. & Path & Path coefficients $(\beta)$ & T-Value & Comments \\
\hline H1 & FV $>$ BI & 0.189 & 3.494 & Supported \\
\hline H2 & SV -> BI & 0.298 & 6.276 & Supported \\
\hline H3 & EV -> BI & 0.149 & 3.773 & Supported \\
\hline H4 & EPV -> BI & 0.038 & 0.693 & Not Supported \\
\hline H5 & SC -> RC & 0.105 & 2.683 & Supported \\
\hline H6 & INT -> RC & 0.551 & 11.713 & Supported \\
\hline H7 & PR -> RC & 0.198 & 3.925 & Supported \\
\hline H8 & TA $>$ RC & 0.042 & 0.804 & Not Supported \\
\hline H9 & RC $>$ BI & 0.216 & 3.513 & Supported \\
\hline
\end{tabular}

$\mathrm{R}^{2}$ for $\mathrm{RC}=0.417, \mathrm{R}^{2}$ for $\mathrm{BI}=0.597$

\section{Discussions AND IMPLiCATIONS FOR TheORY ANd PraCtice}

The primary purpose of this study is to determine the critical factors affecting the e-tax systems' acceptance and resistance intention in Bangladesh from the perspective of dual-factor theory. In the beginning, we examined the connection between the four enablers (functional value, social value, emotional value, and epistemic value) and usage intention. Secondly, the four inhibitors (switching costs, inertia, perceived risk, and technology anxiety) and usage resistance were analyzed. Lastly, we examined the usage intention and usage resistance relationship regarding the e-tax system.

Among the enablers, functional value, social value, and emotional value were pointed as a crucial factor to affect the taxpayer's behavioral intention using the e-tax system positively. Specifically, the result provides strong support for $\mathrm{H} 1$ that suggests that the e-tax system's functional value is positively incorporated with usage intention $(\beta=0.189, \mathrm{t}=3.494)$. Such substantial positive impacts signify that the e-tax system is convenient and advantageous for the taxpayers. It offers taxpayers convenience through waiting-time reduction and quick response. Likewise, the relationship between social value and users' e-tax system usage intention was analyzed in Hypothesis 2 and was proved statistically significant $(\beta=0.298, t=6.276)$. It implies that the use of new technology-oriented services may express personality, status, and image publicly. Taxpayer's perceived that the e-tax system is a modern e-government platform and is getting more and more attention every day. Hence, using an innovative e-tax system would promote their self-image in the society. Besides, when the users find that colleagues, friends, and family members are using the new online tax system, they will be more likely to feel social pressure and more willing to use the system.

Hypothesis 3, which suggested a positive relationship between emotional value and the e-tax system usage intention, was also supported by the study results $(\beta=0.149, \mathrm{t}=3.773)$. This implies that the e-tax system is quick, real-time, effortless, corruption-free, and gets access to the system wherever and whenever the users wish to use it. Consequently, all of these benefits and utilities, directly and indirectly, arouse emotion towards using the e-tax system. Also, the relationship between epistemic value and e-tax system usage intention was statistically rejected $(\beta=0.038$, $\mathrm{t}=0.693$ ). One possible reason is that the existence of epistemic value is temporary as it vanishes as soon as the trial period ends [25]. The epistemic aspect in the e-tax system reflects noveltyseeking, which may influence the trial behavior without significant stimulation for using the system for a long period. Hence, the e-tax system's adoption is beneficial, easy to use, accepted 
by society, and arouse emotion is vital for taxpayers to submit their tax returns online than novelty or innovation willingly. Finally, our findings are consistent with prior research from different innovative technology adoption contexts, including e-government systems [9, 42, 43, 45].

On the other hand, this study proves that the users' usage resistance happens because of switching costs, inertia, perceived risk, and technology anxiety among the inhibitors under review. The results of Hypothesis 5 show a positive relationship between switching costs and usage resistance intention $(\beta=0.105, \mathrm{t}=2.683)$. In our study context, as users do not know about the new e-tax system well, they may get dissatisfied sensing uncertainties. This may lead to user resistance. Further, it must have taken a lot of time and effort for the users to learn the current methods. Thus, switching to the new e-tax system can affect their contemporary working style, which increases the switching cost further, leading to user resistance. Likewise, the relationship between inertia and usage resistance was proved statistically significant $(\beta=0.551, t=11.713)$. This may be because the e-tax system is a comparatively new e-government initiative in Bangladesh, and for a long time, citizens are attached to traditional service. As a result, citizens are reluctant to change the traditional tax return system $[44,48]$.

Besides, our study findings supported Hypothesis 7, which demonstrated a positive relationship between perceived risk and resistance to change $(\beta=0.198, t=3.925)$, validating the previous studies' findings [85-87]. It implies that taxpayers are concerned with their privacy and security, which will intensify their resistance to adopt the e-tax system. Moreover, the study could not recognize any significant relationship between technology anxiety and the e-tax system usage resistance $(\beta=0.042, t=.0804)$. This may be because of the increased usage of computers, laptops, smartphones, and the Internet; the users are getting more familiar with information technology and IS. As a result, they may be less concerned about the anxiety related to an onlineplatform like the e-tax system.

Finally, the finding also suggested that resistance had a great impact on the e-tax system usage intention. Thus, hypothesis 9 was proved $(\beta=0.216, \mathrm{t}=3.513)$, confirming the results of earlier studies [88-90]. This is due to the reason that e-tax service is a comparatively new online service platform from the government; citizens are still not familiar with this system. Similarly, trust issues regarding the government security system and lack of awareness regarding perceived value provided by the e-tax system are also creating resistance among users. Most importantly, citizens are accustomed to the traditional service for a long time, and they are not sure of the outcome of the new e-tax system causing the status quo and leading to userresistance to use.

\subsection{Theoretical implications}

The current research has several findings and implications that will be beneficial to many researchers. The key contribution lies in the synthesis of technological resistance and adoption theories for exploring the way consumers perceive the transition altogether in digital technology. From a dual-factor perspective, using the literature of technology acceptance to apply and amplify the related principles of SQB theory, the research also helps by running and evaluating the established model using a study design that gives less priority to user resistance literature. Besides, theoretical guidance is provided to academics who can help to encourage users to use new IT products or services.

Moreover, in prior studies, enablers and inhibitors have not been explicitly described or adequately analyzed. We, therefore, make a contribution to the research on IS as well as the dualfactor theoretical framework through specifically developing and evaluating the enablers and 
International Journal of Managing Public Sector Information and Communication Technologies (IJMPICT) Vol. 12, No.1, March 2021

inhibitors. This study demonstrates how functional value, social value, and emotional value are crucial factors to promote system usage. The inhibitors' purpose (as in switching costs, perceived risks, and inertia) as influencing factors will be immensely impactful for citizens' e- tax system usage resistance. This result may be of relevance and inspire the researchers associated with designing an IS acceptance and resistance model.

Finally, this study has a crucial theoretical influence on SQB theory, which has been used to plan bias against preserving the status quo regarding human decision-making and actions. Resuming the precedent studies, the current research has shown the implication of SQB theoriesin IS studies for understanding consumer resistance to a newly introduced IS service, such as an e-tax system. This accurate and legitimate instrument, therefore, offers a handful of a method for researchers in assessing the user behavior and to clarify, interpret, and evaluate variations in the results of the analysis. Finally, due to a similar approach, the results of this study could easily be adapted to support other developing nations to prepare and implement government online services.

\subsection{Practical implications}

Along with several theoretical contributions, this study also offers several policy guidelines for government policymakers and system developers. Findings suggest that the functional value is a key factor for e-tax system usage intention. The tax authority should discuss different ways of improving the e-tax systems' practical elements. Functional value can be improved through enhancing the design of a website and guaranteeing the reliability and updating of informationis [91]. The design has to represent the subscribers' viewpoint regarding the online method and give quick accessibility and smooth online facilities 24/7. The research also indicates that consumer social importance is a good predictor of intended use. E-tax is considered to represent a new government platform that draws more and more interest among taxpayers and taxpayers use the mechanism as a means of communicating identity, position, and image in a public setting [43]. The government should also provide social acceptance, rewards, and incentives for users of the e-tax system to maximize social value.

Additionally, the emotional value was considered to be significant for the prediction of the users' e-tax system usage intention. The tax authority should also investigate the ways of generating optimistic emotions for the e-tax system. Compliance with tax returns should be made more seamless and hassle free to taxpayers, and the e-tax systems must be compatible and incorporated with the contemporary natural environment of the taxpayers [92]. The natural environment comprises accounting and tracking social media like Facebook and solutions to software [92]. Further, findings also indicate that perceived risk is significant and responds positively to use resistance. Governments should also emphasize the importance of online networks for reducing risk perceptions [14]. Besides, tax officials should take steps to reduce consumer issues by improving the security of e-tax systems and ensuring the privacy and protection of users of their personal information. Moreover, the government should take legal action against and administer exemplary penalties for hackers and reimburse offenders. Advertising campaigns are also essential for the distribution of information on security and privacy initiatives to citizens. The tax authority must also ensure a secure and trouble-free e-tax system.

Inertia was found significant towards resistance to use the e-tax system. To reduce inertia, awareness campaigns should be organized for people having inert characteristics to learn more about the e-tax systems' benefits and advantages. The inertia should be reduced as well by providing incentives (e.g. tax rebate) for e-tax system usage. At the same time, several training programs should be organized to educate taxpayers. Further, usages benefit should be 
International Journal of Managing Public Sector Information and Communication Technologies (IJMPICT) Vol. 12, No.1, March 2021

communicated clearly to the users before the e-tax system implementation to break the inert behavior.

Moreover, the research recommends that switching costs possess a significant determinant of resistance to use the e-tax system. Higher switching costs weaken the intention and increase resistance to change [89]. Therefore, the tax agency should use various channels of promotion (e.g. mass media and expert opinion) to communicate with potential adopters simultaneously to reduce the switching costs and overcome the resistance they may have about adopting the e-tax system. Besides, keeping online assistance or a hotline can enable the users to get help whenever they face trouble using the system. This will significantly reduce switching costs.

Finally, resistance was proved to be statistically significant in assessing the user's e-tax system usage intention. High resistance behavior diminishes the purpose of usage, but user decisions usually depend on the benefits sought and not on the losses [9]. Governments must also emphasize the potential advantage of online platforms to minimize resistance. Also, the tax authority should take initiatives to reduce the grievances of users by improving the security of etax systems and ensuring the privacy and protection of users of their personal information. Additionally, a tax agency can reduce the resistance of users by providing well-designed learning programs with appropriate material that can instruct users step by step, minimize time and effort to understand a new method, reduce confusion and fear, and connect users' existing skills.

\subsection{Study limitations and future research directions}

This research possesses certain limitations. First, the research ignores several essential enablers and inhibitors that had the potential to explain acceptance and resistance behavior even though it includes the constructs that are relevant to explain the acceptance and resistance behavior of an individual. Extending the study through adding enablers such as trust in government, selfefficacy, compatibility [93, 94], relative advantage and facilitating condition [95], satisfaction [96]; and inhibitors such as habit, anchoring effects and optimism bias should be considered in future researches for the improvement of the theoretical models' explanatory ability [90, 97, 98]. Second, the survey was based on a specific country like Bangladesh that suggests that this study exposes the specific nations' scenario only. Thus, this study indicates that further research should be performed using other different country data. Third, the results could be limited to describing citizens' acceptance and resistance of the e-tax system only. To which extent the study-findings and recommendations can get applied to other e-government systems remain unchecked. Hence, future research needs to examine the model to other e-government contexts for verifying the findings. Third, the research was conducted based on a survey approach for data collection. Consequently, the results should be viewed considering the limitations of this approach, generally considered as a complete error of survey [99]. Future research should also be evaluating a conceptual model based on different forms of design methods, as in experimentsand observations, to make the results more reliable and valid [100]. Finally, there is a significant contrast between what people declare (intention to use) and what they actually do (effective use). As a result, our results must be viewed with caution.

\subsection{Conclusion}

This study contributes to the current body of knowledge in respect to reducing the research gap by investigating the causal association between intention to use and resistance to the use of the etax system in Bangladesh. The uniqueness of this study is that it offers a comprehensive view of the critical factor (e.g. enablers and inhibitors) that determines the technical purpose to use and the resistance to use of the e-tax system. The results indicate that functional value, social value 
International Journal of Managing Public Sector Information and Communication Technologies (IJMPICT) Vol. 12, No.1, March 2021

and emotional value make it worthwhile while the resistance to use limits the use of the e-tax system. This also found a number of inhibiting factors (e.g., switching costs, inertia and perceived risk), creating high resistance among users against e-tax system use. We hope that this study will stimulate future interest in the technology acceptance and resistance phenomena and motivate researchers to examine in greater depth this unexplored yet potentially fertile area of research.

\section{REFERENCES}

[1] M. N. Hossain, M. S. Talukder, M. R. Hoque, and Y. Bao, "The use of open government data to citizen empowerment: an empirical validation of a proposed model," Foresight, vol. 20, no. 6, pp. 665-680, 2018.

[2] M. F. Rahman, M. S. Talukder, and Y. Lanrong, "Why do citizens use e-tax system? Extending the technology continuance theory," International Journal of Research in Business and Social Science (2147- 4478), vol. 9, no. 7, pp. 177- 189, 12/12 2020.

[3] S. ElMassah and M. Mohieldin, "Digital transformation and localizing the Sustainable Development Goals (SDGs)," Ecological Economics, vol. 169, p.106490, 2020/03/01/ 2020.

[4] D. Rombach and P. Steffens, "e-Government," in Springer Handbook of Automation, S. Y. Nof, Ed. Berlin, Heidelberg: Springer Berlin Heidelberg,2009, pp. 1629-1643.

[5] S. Talukder, R. Chiong, S. Dhakal, G. Sorwar, and Y. Bao, "A two-stage structural equation modelingneural network approach for understanding andpredicting the determinants of m-government service adoption," Journal of Systems and Information Technology, vol. 21, no. 4, pp. 419-438, 2019.

[6] N. Veeramootoo, R. Nunkoo, and Y. K. Dwivedi, "What determines success of an e-government service? Validation of an integrative model of e-filing continuance usage," Government Information Quarterly, vol. 35, no. 2, pp. 161-174, 2018/04/01/ 2018.

[7] J.-R. Fu, C.-K. Farn, and W.-P. Chao, "Acceptance of electronic tax filing: A study of taxpayer intentions," Information \& Management, vol. 43, no. 1, pp.109-126, 2006/01/01/ 2006.

[8] A. R. Ambali, "E-government policy: Ground issues in e-filing system," in European Journal of Social Sciences, 2009, vol. 11, no. 2, pp. 249-266.

[9] M. S. Akram, A. Malik, M. A. Shareef, and M. Awais Shakir Goraya, "Exploringthe interrelationships between technological predictors and behavioral mediatorsin online tax filing: The moderating role of perceived risk," Government Information Quarterly, vol. 36, no. 2, pp. 237-251, 2019.

[10] F. Bélanger and L. Carter, "Trust and risk in e-government adoption," (in English), Journal of Strategic Information Systems, vol. 17, no. 2, pp. 165-176,Jun 2008.

[11] H. Antoine and R. Alice, "Inhibitors and Enablers of Public E-Services in Lebanon," Journal of Organizational and End User Computing (JOEUC), vol.24, no. 3, pp. 45-68, 2012.

[12] Y. K. Dwivedi, V. Weerakkody, and M. Janssen, "Moving towards maturity:challenges to successful egovernment implementation and diffusion," ACM SIGMIS Database: the DATABASE for Advances in Information Systems, vol. 42, no. 4, pp. 11-22, 2012.

[13] A. K. M. N. Islam, "Investigating e-learning system usage outcomes in the university context," Computers \& Education, vol. 69, pp. 387-399, 2013/11/01/2013.

[14] M. S. Talukder, L. Shen, M. F. Hossain Talukder, and Y. Bao, "Determinants of user acceptance and use of open government data (OGD): An empirical investigation in Bangladesh," Technology in Society, vol. 56, pp. 147-156, 2018/09/22/ 2019.

[15] J.-M. Tsai, M.-J. Cheng, H.-H. Tsai, S.-W. Hung, and Y.-L. Chen, "Acceptance and resistance of telehealth: The perspective of dual-factor concepts in technology adoption," International Journal of Information Management, vol.49, pp. 34-44, 2019/12/01/ 2019.

[16] H.-W. Kim and A. Kankanhalli, "Investigating User Resistance to Information Systems Implementation: A Status Quo Bias Perspective," MIS Quarterly, vol.33, no. 3, pp. 567-582, 2009.

[17] S. Talukder, R. Chiong, B. Corbitt, and Y. Bao, "Critical Factors Influencing theIntention to Adopt MGovernment Services by the Elderly," Journal of Global Information Management, vol. 28, no. 4, pp. 419-438, 2019.

[18] R. T. Cenfetelli, "Inhibitors and enablers as dual factor concepts in technology usage," Journal of the Association for Information Systems, vol. 5, no. 11, p. 16,2004.

[19] F. Davis, "Perceived usefulness, perceived ease of use, and user acceptance of information 
International Journal of Managing Public Sector Information and Communication Technologies (IJMPICT) Vol. 12, No.1, March 2021 technology," MIS Quarterly, vol. 13, no. 3, pp. 319-340, 1989.

[20] A. Bhattacherjee, J. Perols, and C. Sanford, "Information Technology Continuance: A Theoretic Extension and Empirical Test," Journal of ComputerInformation Systems, vol. 49, no. 1, pp. 17-26, 2008/09/01 2008.

[21] M. Rey-Moreno, J. A. Felício, C. Medina-Molina, and R. Rufín, "Facilitator and inhibitor factors: Adopting e-government in a dual model," Journal of Business Research, vol. 88, pp. 542-549, 2018.

[22] A. K. M. Najmul Islam, "Sources of satisfaction and dissatisfaction with a learning management system in post-adoption stage: A critical incident technique approach," Computers in Human Behavior, vol. 30, pp. 249-261,2014/01/01/2014.

[23] A. Bhattacherjee, J. Perols, and C. Sanford, "Information Technology Continuance: A Theoretic Extension and Empirical Test," Journal of ComputerInformation Systems, vol. 49, no. 1, pp. 17-26, 2015.

[24] A. Bhattacherjee and N. Hikmet, "Reconceptualizing organizational support and its effect on information technology usage: Evidence from the health care sector," (in English), Journal of Computer Information Systems, vol. 48, no. 4, pp. 69-76, Sum 2008.

[25] J. N. Sheth, B. I. Newman, and B. L. Gross, "Why we buy what we buy: A theory of consumption values," Journal of business research, vol. 22, no. 2, pp.159-170, 1991.

[26] J. R. Fu, Farn, C.-K., \& Chao, W. P., "Acceptance of electronic tax filing: A study of taxpayer intentions. ," Information Management,, vol. 43, pp., 109-126., 2006.

[27] T. Santhanamery and T. Ramayah, "Explaining and predicting users' continuance usage intention toward e-filing utilizing technology continuance theory," in Encyclopedia of Information Science and Technology, Fourth Edition: IGI Global, 2018, pp. 831-846.

[28] Y.-S. Wang, "The adoption of electronic tax filing systems: an empirical study," Government Information Quarterly, vol. 20, no. 4, pp. 333-352, 2003.

[29] T. Santhanamery and T. Ramayah, "Trust in the system: The mediating effect ofperceived usefulness of the e-filing system," in User Centric E-Government: Springer, 2018, pp. 89-103.

[30] L. Carter, L. Schaupp, and A. Evans, "Antecedents to e-File adoption: the US perspective," in Proceedings of the 41st Annual Hawaii International Conference on System Sciences (HICSS 2008), 2008, pp. 216-216: IEEE.

[31] L. Carter, L. C. Schaupp, and M. E. McBride, "The US e-file initiative: An investigation of the antecedents to adoption from the individual taxpayers' perspective," e-Service Journal: A Journal of Electronic Services in the Publicand Private Sectors, vol. 7, no. 3, pp. 2-19, 2011.

[32] W. Bhuasiri, H. Zo, H. Lee, and A. P. Ciganek, "User Acceptance of e- government Services: Examining an e-tax Filing and Payment System in Thailand," Information Technology for Development, vol. 22, no. 4, pp. 672-695,2016.

[33] J. Nel and C. Boshoff, "Status quo bias and shoppers' mobile website purchasing resistance," European Journal of Marketing, 2020.

[34] L. C. Schaupp, L. Carter, and M. E. McBride, "E-file adoption: A study of U.S.taxpayers' intentions," Computers in Human Behavior, vol. 26, no. 4, pp. 636- 644, 2010.

[35] P.-J. Hsieh, "An empirical investigation of patients' acceptance and resistancetoward the health cloud: The dual factor perspective," Computers in Human Behavior, vol. 63, pp. 959-969, 2016/10/01/ 2016.

[36] A. Bhattacherjee and N. Hikmet, "Physicians' resistance toward healthcare information technology: a theoretical model and empirical test," European Journal of Information Systems, vol. 16, no. 6, pp. 725-737, 2007/12/01 2007.

[37] V. Venkatesh and S. A. Brown, "A longitudinal investigation of personal computers in homes: Adoption determinants and emerging challenges," MISquarterly, pp. 71-102, 2001.

[38] A. Bhattacherjee and N. Hikmet, "Enabelers and inhibitors of healthcare information technology adoption: toward a dual-factor model," AMCIS 2008Proceedings, p. 135, 2008.

[39] A. K. M. Najmul Islam, R. Cenfetelli, and I. Benbasat, "Organizational buyers' assimilation of B2B platforms: Effects of IT-enabled service functionality," TheJournal of Strategic Information Systems, vol. 29, no. 1, p. 101597, 2020/03/01/2020.

[40] A. Bhattacherjee and C.-P. Lin, "A unified model of IT continuance: threecomplementary perspectives and crossover effects," European Journal ofInformation Systems, vol. 24, no. 4, pp. 364-373, 2015.

[41] J. Hedman and G. Gimpel, "The adoption of hyped technologies: a qualitative study," Information Technology and Management, vol. 11, no. 4, pp. 161-175,2010.

[42] O. Turel, A. Serenko, and N. Bontis, "User acceptance of hedonic digital artifacts: A theory of 
International Journal of Managing Public Sector Information and Communication Technologies (IJMPICT) Vol. 12, No.1, March 2021

consumption values perspective," Information \& Management, vol. 47, no. 1, pp. 53-59, 2010/01/01/ 2010.

[43] H.-Y. Wang, C. Liao, and L.-H. Yang, "What affects mobile application use? Theroles of consumption values," International Journal of Marketing Studies, vol. 5,no. 2, p. 11, 2013.

[44] T. T. Goh, N. M. Suki, and K. Fam, "Exploring a consumption value model forIslamic mobile banking adoption," Journal of Islamic Marketing, 2014.

[45] X. Xiao, J. Hedman, and E. Runnemark, "Use of Payment Technology: APerspective Based on Theory of Consumption Value," in ECIS, 2015.

[46] W. Samuelson and R. Zeckhauser, "Status quo bias in decision making," Journal of Risk and Uncertainty, vol. 1, no. 1, pp. 7-59, 1988/03/01 1988.

[47] B. Inder and T. O'Brien, "The endowment effect and the role of uncertainty," Bulletin of Economic Research, vol. 55, no. 3, pp. 289-301, 2003.

[48] G. L. Polites and E. Karahanna, "Shackled to the status quo: The inhibiting effects of incumbent system habit, switching costs, and inertia on new systemacceptance," MIS quarterly, pp. 21-42, 2012.

[49] J. N. Sheth, B. I. Newman, and B. L. Gross, "Consumption values and market choice. Cincinnati," Ohio: South Westerb Publishing, 1991.

[50] M. A. Shareef, Kumar, V., Kumar, U., \& Dwivedi, Y. K., "E-government adoption model (GAM): Differing service maturity levels.," GovernmentInformation Quarterly., 2011.

[51] J.-Y. Tzeng, "Perceived values and prospective users' acceptance of prospectivetechnology: The case of a career eportfolio system," Computers \& Education, vol. 56, no. 1, pp. 157-165, 2011.

[52] A. C. van Riel and M. Pura, "Linking perceived value and loyalty in location-based mobile services," Managing Service Quality: An InternationalJournal, 2005.

[53] J. C. Sweeney and G. N. Soutar, "Consumer perceived value: The development of a multiple item scale," Journal of Retailing, vol. 77, no. 2, pp. 203-220, 2001/06/01/ 2001.

[54] K. Bodker, F. Kensing, and J. Simonsen, Participatory IT design: designing for business and workplace realities. MIT press, 2009.

[55] M. F. Rahman, M. S. Talukder, Y. Lanrong, and A. Khayer, "Why do citizens use e-tax system? Extending the technology continuance theory," International Journal of Research in Business and Social Science (2147- 4478), vol. 9, no. 7, pp. 177-189, 12/17 2020.

[56] K. Yang and L. D. Jolly, "The effects of consumer perceived value and subjective norm on mobile data service adoption between American and Koreanconsumers," Journal of Retailing and Consumer Services, vol. 16, no. 6, pp. 502-508, 2009/11/01/ 2009.

[57] R. Chen and S. Sharma, "Understanding member use of social networking sites: A value analysis," Communications of the Association for Information Systems, vol. 33, no. 1, p. 6, 2013.

[58] S. Kushwah, A. Dhir, and M. Sagar, "Ethical consumption intentions and choice behavior towards organic food. Moderation role of buying and environmental concerns," Journal of Cleaner Production, vol. 236, p. 117519, 2019/11/01/ 2019.

[59] Z. Hu, Y. Bao, R. Chiong, T. J. J. o. S. S. Xiong, and Complexity, "Profit guided or statistical error guided? a study of stock index forecasting using support vector regression," journal article vol. 30, no. 6, pp. 1425-1442, December 012017.

[60] Y. Tang and P. Forster, "Exploring the value structure behind mobile auction adoption intention," in AMCIS Proceedings, 2007, p. 499.

[61] T. A. Burnham, J. K. Frels, and V. Mahajan, "Consumer Switching Costs: ATypology, Antecedents, and Consequences," Journal of the Academy of Marketing Science, vol. 31, no. 2, pp. 109-126, 2003/04/012003.

[62] C. Bradbury-Jones, J. Taylor, and O. Herber, "How theory is used and articulated in qualitative research: Development of a new typology," Social Science \& Medicine, vol. 120, pp. 135-141, 2014/11/01/ 2014.

[63] A. Bhattacherjee and A. Barfar, "Information technology continuance research:current state and future directions," vol. 21, no. 2, pp. 1-18, 2011.

[64] L. Lucia-Palacios, R. Pérez-López, and Y. Polo-Redondo, "Enemies of cloud services usage: inertia and switching costs," Service Business, vol. 10, no. 2, pp.447-467, 2016/06/01 2016.

[65] S. McLeod, "Information processing," Simply psychology, 2008.

[66] J.-H. Huang, Y.-R. Lin, and S.-T. Chuang, "Elucidating user behavior of mobile learning: A perspective of the extended technology acceptance model," (in English), Electronic Library, vol. 25, no. 5, pp. 585-598, 2007. 
International Journal of Managing Public Sector Information and Communication Technologies (IJMPICT) Vol. 12, No.1, March 2021

[67] T.-F. Kummer, J. Recker, and M. Bick, "Technology-induced anxiety: Manifestations, cultural influences, and its effect on the adoption of sensor- based technology in German and Australian hospitals," Information \& Management, vol. 54, no. 1, pp. 73-89, 2017.

[68] G. M. Marakas and S. Hornik, "Passive resistance misuse: overt support and covert recalcitrance in IS implementation," European Journal of Information Systems, vol. 5, no. 3, pp. 208-219, 1996/09/01 1996.

[69] H.-W. Kim and A. Kankanhalli, "Investigating user resistance to information systems implementation: A status quo bias perspective," MIS quarterly, pp. 567-582, 2009.

[70] ADB. Comparative Analysis of Tax Administration in Asia and the Pacific [Online]. Available: https://www.adb.org/sites/default/files/publication/569626/tax-administration- asia-pacific-2020.pdf

[71] S. Parvez, "The curious case of NBR's online tax return filing project," in The Daily Star, ed. Dhaka, Bangladesh: The Daily star, 2020.

[72] N. Kumar, L. W. Stern, and J. C. Anderson, "Conducting Interorganizational Research Using Key Informants," vol. 36, no. 6, pp. 1633-1651, 1993.

[73] C. J. Dommeyer*, P. Baum, R. W. Hanna, and K. S. Chapman, "Gathering faculty teaching evaluations by in-class and online surveys: their effects on response rates and evaluations," Assessment \& Evaluation in Higher Education, vol. 29, no. 5, pp. 611-623, 2004.

[74] D. S. Fike, D. J. Doyle, and R. J. Connelly, "Online vs. Paper Evaluations of Faculty: When Less Is Just as Good," Journal of Effective Teaching, vol. 10, no.2, pp. 42-54, 2010.

[75] F. Liu, X. Zhao, P. Y. Chau, and Q. Tang, "Roles of perceived value and individual differences in the acceptance of mobile coupon applications," InternetResearch, 2015.

[76] S. Z. Ahmad and K. Khalid, "The adoption of M-government services from the user's perspectives: Empirical evidence from the United Arab Emirates," International Journal of Information Management, vol. 37, no. 5, pp. 367-379,2017.

[77] M. Kurfalı, A. Arifoğlu, G. Tokdemir, and Y. Paçin, "Adoption of e-governmentservices in Turkey," Computers in Human Behavior, vol. 66, pp. 168-178, 2017.

[78] W. W. Chin, "The partial least squares approach to structural equation modeling," Modern methods for business research, vol. 295, no. 2, pp. 295-336,1998.

[79] J. F. Hair Jr, G. T. M. Hult, C. Ringle, and M. Sarstedt, A primer on partial least squares structural equation modeling (PLS-SEM). London: Thousand Oaks: Sage Publications, 2016.

[80] M. Tenenhaus, S. Amato, and V. Esposito Vinzi, "A global goodness-of-fit index for PLS structural equation modelling," in Proceedings of the XLII SIS scientificmeeting, 2004, vol. 1, no. 2, pp. 739 742.

[81] J. Hair, R. Anderson, R. Tatham, and W. Black, "Multivariate data analysis 6thedition prentice hall," New Jersey, 2006.

[82] E. G. Carmines and R. A. Zeller, Reliability and validity assessment. Sagepublications, 1979.

[83] J. Henseler, C. M. Ringle, and R. R. Sinkovics, "The use of partial least squares path modeling in international marketing," Advances in international marketing,vol. 20, no. 1, pp. 277-319, 2009.

[84] B. Efron and R. J. Tibshirani, An introduction to the bootstrap. CRC press, 1994.

[85] A. C. Azmi and N. L. Bee, "The Acceptance of the e-Filing System by Malaysian Taxpayers: A Simplified Model," Electronic Journal of e- Government, vol. 8, no. 1, 2010.

[86] M. S. Featherman and P. A. Pavlou, "Predicting e-services adoption: a perceived risk facets perspective," International journal of human-computer studies, vol. 59, no. 4, pp. 451-474, 2003.

[87] S. Mohtar and M. Abbas, "Consumer resistance to innovation due to perceived risk: Relationship between perceived risk and consumer resistances to innovation," Journal of Technology and Operations Management, vol. 10, no. 1,pp. 1-13, 2020.

[88] M. D. Norzaidi, S. C. Chong, and M. I. Salwani, "Perceived resistance, user resistance and managers' performance in the Malaysian port industry," in AslibProceedings, 2008: Emerald Group Publishing Limited.

[89] H.-W. Kim, "The effects of switching costs on user resistance to enterprise systems implementation," IEEE Transactions on Engineering Management, vol.58, no. 3, pp. 471-482, 2010.

[90] K. Lee and K. Joshi, "Examining the use of status quo bias perspective in IS research: need for reconceptualizing and incorporating biases," Information Systems Journal, vol. 27, no. 6, pp. 733-752, 2017.

[91] X. Xu, X. Cao, and L. Zhao, "Comparison of rice husk- and dairy manure- derived biochars for simultaneously removing heavy metals from aqueoussolutions: Role of mineral components in 
International Journal of Managing Public Sector Information and Communication Technologies (IJMPICT) Vol. 12, No.1, March 2021 biochars," Chemosphere, vol. 92, no.8, pp. 955-961, 2013/08/01/ 2013.

[92] O. Publishing, Development Co-operation Report 2016-The Sustainable Development Goals as Business Opportunities. OECD Publishing, 2016.

[93] T. Zhou and H. Li, "Understanding mobile SNS continuance usage in China from the perspectives of social influence and privacy concern," Computers in Human Behavior, vol. 37, pp. 283-289, 2014/08/01/ 2014.

[94] M. Janssen, N. P. Rana, E. L. Slade, and Y. K. Dwivedi, "Trustworthiness of digital government services: deriving a comprehensive theory through interpretive structural modelling," Public Management Review, vol. 20, no. 5,pp. 647-671, 2018.

[95] J.-W. Lian and D. C. Yen, "Online shopping drivers and barriers for older adults: Age and gender differences," Computers in Human Behavior, vol. 37, pp. 133- 143, 2014.

[96] P.-J. Hsieh and W.-S. Lin, "Explaining resistance to system usage in the PharmaCloud: A view of the dual-factor model," Information \& Management, vol. 55, no. 1, pp. 51-63, 2018.

[97] X. Zhang, X. Guo, Y. Wu, K.-h. Lai, and D. Vogel, "Exploring the inhibitors of online health service use intention: a status quo bias perspective," Information \&Management, vol. 54, no. 8, pp. 987-997, 2017.

[98] L. C. Schaupp and L. Carter, "The impact of trust, risk and optimism bias on E- file adoption," Information Systems Frontiers, vol. 12, no. 3, pp. 299-309, 2010.

[99] S. Eckman and E. d. Leeuw, "Editorial - Special Issue on Total Survey Error(TSE)," (in English), vol. 33, no. 2, p. 301, 2017.

[100] A. O. de Guinea and M. L. Markus, "Why Break the Habit of a Lifetime? Rethinking the Roles of Intention, Habit, and Emotion in Continuing Information Technology Use," MIS Quarterly, vol. 33, no. 3, pp. 433-444, 2009.

[101] P.-C. Lin and Y.-H. Huang, "The influence factors on choice behavior regardinggreen products based on the theory of consumption values," Journal of Cleaner Production, vol. 22, no. 1, pp. 11-18, 2012/02/01/ 2012.

[102] M. A. Jones, D. L. Mothersbaugh, and S. E. Beatty, "Why customers stay: measuring the underlying dimensions of services switching costs and managingtheir differential strategic outcomes," Journal of business research, vol. 55, no.6, pp. 441-450, 2002.

[103] L. C. Schaupp, L. Carter, and M. E. McBride, "E-file adoption: A study of UStaxpayers' intentions," Computers in Human Behavior, vol. 26, no. 4, pp. 636-644, 2010.

[104] N. P. Rana, \& Dwivedi, Y. K. , " Citizen's adoption of an e-government system:Validating extended social cognitive theory (SCT)," Government Information Quarterly,, vol. 32(2), pp. 172-181., 2015.

[105] C.-M. C. Shin-Yuan Hung, Ting-Jing Yu, "Determinants of user acceptance of the e-Government services: The case of online tax filing and payment system," Government Information Quarterly, vol. 23, no. 97-122, 2006.

\section{Appendix A. Measurement instruments and Items loadings}

\begin{tabular}{|c|c|c|c|}
\hline Variable Name & Corresponding Items & Loadings & Item Sources \\
\hline $\begin{array}{l}\text { Functional values } \\
(\mathrm{FV})\end{array}$ & $\begin{array}{l}\text { FV1. E-tax systems are very convenient for meFV2. } \\
\text { E-tax systems suit my work and lifestyle FV3. E- } \\
\text { tax systems increase my productivity } \\
\text { FV4. E-tax systems fulfill my needs well }\end{array}$ & $\begin{array}{l}0.857 \\
0.818 \\
0.860 \\
0.859\end{array}$ & $\begin{array}{l}\text { van Riel and Pura } \\
\text { [52] } \\
\text { Sweeney and } \\
\text { Soutar [53] }\end{array}$ \\
\hline $\begin{array}{l}\text { Social } \\
\text { (SV) }\end{array}$ & $\begin{array}{l}\text { SV1. Using e-tax system helps me to feel accepted } \\
\text { by others. } \\
\text { SV2. Using e-tax systems would give me a better } \\
\text { image and a higher social status. } \\
\text { SV3. Using e-tax systems allows me to contribute } \\
\text { to society and community }\end{array}$ & $\begin{array}{l}0.822 \\
0.820 \\
0.763\end{array}$ & $\begin{array}{l}\text { van Riel and Pura } \\
\text { [52] } \\
\text { Sweeney and } \\
\text { Soutar [53] }\end{array}$ \\
\hline $\begin{array}{l}\text { Emotional Value } \\
(\mathrm{EV})\end{array}$ & $\begin{array}{l}\text { EV1. I am comfortable with e-tax system. } \\
\text { EV2. The use of e-tax systems gave me a positive } \\
\text { feeling. } \\
\text { EV3. Using the e-tax systems would make me feel }\end{array}$ & $\begin{array}{l}0.870 \\
0.777 \\
0.922\end{array}$ & {$[25,101]$} \\
\hline
\end{tabular}


International Journal of Managing Public Sector Information and Communication Technologies (IJMPICT) Vol. 12, No.1, March 2021

\begin{tabular}{|c|c|c|c|}
\hline & good. & & \\
\hline $\begin{array}{l}\text { Epistemic value } \\
(\mathrm{EPV})\end{array}$ & $\begin{array}{l}\text { EPV1. I use e-tax systems because I am always } \\
\text { highly curious to try something new } \\
\text { EPV2. I use e-tax systems because I like to keep } \\
\text { abreast of technological trends } \\
\text { EPV3. I am able to learn new things when I use e- } \\
\text { tax systems }\end{array}$ & $\begin{array}{l}0.776 \\
0.853 \\
0.793\end{array}$ & $\begin{array}{l}\text { Wang, et al. [43] } \\
\text { Sweeney and } \\
\text { Soutar [53] }\end{array}$ \\
\hline Inertia (INT) & $\begin{array}{l}\text { INT1. I will continue using the traditional tax } \\
\text { service because changing the system is stressful. } \\
\text { INT2. I will continue using the traditional services } \\
\text { because I enjoy using the channel. } \\
\text { RC3. I will continue using the traditional tax } \\
\text { service even though I know that this system is not } \\
\text { the best way of doing things. }\end{array}$ & $\begin{array}{l}0.753 \\
0.842 \\
0.872\end{array}$ & $\begin{array}{l}\text { Polites and } \\
\text { Karahanna [48] } \\
\text { Samuelson and } \\
\text { Zeckhauser [46] }\end{array}$ \\
\hline $\begin{array}{l}\text { Switching Costs } \\
\text { (SC) }\end{array}$ & $\begin{array}{l}\text { SC1. It will take a lot of time and effort to learn } \\
\text { how to use the new online tax filing system. } \\
\text { SC2. I will lose a lot of my work if I am to switch } \\
\text { to the new way of working with the online tax } \\
\text { filing applications } \\
\text { SC3. Switching to new ways of working with } \\
\text { online tax filing application can result in } \\
\text { unexpected hassles } \\
\text { SC4. I am not sure what the level of service would } \\
\text { be if I switched to a new online tax filing service. }\end{array}$ & $\begin{array}{l}0.841 \\
0.815 \\
0.794 \\
0.738\end{array}$ & $\begin{array}{l}\text { Kim and } \\
\text { Kankanhalli [69] } \\
\text { Polites and } \\
\text { Karahanna [48] }\end{array}$ \\
\hline $\begin{array}{l}\text { Perceived Risk } \\
\text { (PR) }\end{array}$ & $\begin{array}{l}\text { PR1: I do not think it is safe to use e-tax methods } \\
\text { because of the privacy and security concerns } \\
\text { PR2: I believe that use of e-tax system may cause } \\
\text { my personal information to be stolen. } \\
\text { PR3: I believe that there could be negative } \\
\text { consequences by using an e-tax system }\end{array}$ & $\begin{array}{l}0.956 \\
0.832 \\
0.842\end{array}$ & $\begin{array}{l}\text { Jones, et al. [102] } \\
\text { Schaupp, et al. } \\
{[103]}\end{array}$ \\
\hline $\begin{array}{l}\text { Technology } \\
\text { Anxiety (TA) }\end{array}$ & $\begin{array}{l}\text { TA1: I feel nervous about using an e-tax system to } \\
\text { file my taxes. } \\
\text { TA2: It scares me to think that I could lose a lot of } \\
\text { information using an e-tax system by hitting the } \\
\text { wrong key. } \\
\text { TA3: I hesitate to use an e-tax system for fear of } \\
\text { making mistakes I cannot correct. }\end{array}$ & $\begin{array}{l}0.873 \\
0.786 \\
0.925\end{array}$ & $\begin{array}{l}\text { Carter, et al. [31] } \\
\text { Rana [104] }\end{array}$ \\
\hline $\begin{array}{l}\text { Resistance } \\
\text { use (RC) }\end{array}$ & $\begin{array}{l}\text { RC1. I don't want the online tax services changing } \\
\text { the way I interact with tax related services. } \\
\text { RC2. I would not change my preference of using } \\
\text { traditional paper based tax service to online tax } \\
\text { system. } \\
\text { RC3. I would not willingly change my preference } \\
\text { of using traditional tax service to online tax system. }\end{array}$ & $\left\{\begin{array}{l}0.863 \\
0.880 \\
0.841\end{array}\right.$ & $\begin{array}{l}\text { Bhattacherjee and } \\
\text { Hikmet [36] } \\
\text { Hsieh [35] }\end{array}$ \\
\hline $\begin{array}{l}\text { Behavioral } \\
\text { intention to use } \\
(\mathrm{BI})\end{array}$ & $\begin{array}{l}\text { BI1. I think the e-tax system is worth using rather } \\
\text { than use any alternative means. } \\
\text { BI2. In the future, I will continue to/consider } \\
\text { adopting the e-tax system. } \\
\text { BI3. I would recommend the e-tax system to others. }\end{array}$ & $\begin{array}{l}0.703 \\
0.927 \\
0.913\end{array}$ & $\begin{array}{l}\text { Shin-Yuan Hung } \\
{[105]} \\
{[6]}\end{array}$ \\
\hline
\end{tabular}




\section{Appendix B. Demographic profile of the respondents}

\begin{tabular}{|lcc|}
\hline Variables & $\mathrm{n}$ & Percentage \\
\hline Gender & 165 & $44 \%$ \\
Female & 257 & $56 \%$ \\
Male & & \\
Age & 74 & $13 \%$ \\
$18-29$ years & 183 & $32 \%$ \\
$30-39$ years & 105 & $37 \%$ \\
$40-49$ years & 52 & $15 \%$ \\
$50-59$ years & 8 & $2 \%$ \\
60 years & & \\
Education level & 45 & $6 \%$ \\
Below Bachelor & 146 & $12 \%$ \\
Bachelor & 231 & $43 \%$ \\
Masters or Higher & & \\
Sector of employment & 93 & $23 \%$ \\
Public sector & 195 & $47 \%$ \\
Private sector & 71 & $16 \%$ \\
Semi-governmental institutions & 63 & $14 \%$ \\
Self-Employed & \\
E-government services use experience & 72 & $54 \%$ \\
Less than 2 years & 254 & $29 \%$ \\
2 - 4 years & 96 & \\
More than 4 years & &
\end{tabular}

\section{Authors}

Md. Faridur Rahman is a doctoral student at the College of Public Administration, Huazhong University of Science and Technology, Wuhan, P.R. of China. He holds a Master's degree in Finance \& Business Management from the University of Bedfordshire, United Kingdom.

Md. Shamim Talukder is currently an Assistant Professor in the Department of Management, North South University, Bangladesh. He received Ph.D. degree major in Management Science and Engineering from the School of Management, Huazhong University of Science and Technology, Wuhan, China and MBA in Management Information Systems from University of Dhaka, Bangladesh. His teaching and research interests include structural equation modelling, neural network modelling, multivariate data analysis, technology acceptance, healthcare technology and open government. His

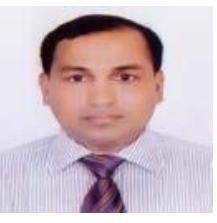
research has been published in journals such as Industrial Management and Data Systems, Technology in Society, Journal of Systems and Information Technology, and Foresight. He serves as a reviewer for many peer review journals including Information Technology and People, the Bottom Line, and the Journal of Systems and Information Technology.

Dr. Yang Lanrong is Associate Professor at the College of Public Administration, Huazhong University of Science and Technology, Wuhan, P.R. of China. Academic Areas: E-government, Theory and Method of Modern Management Technology, Government Procurement.

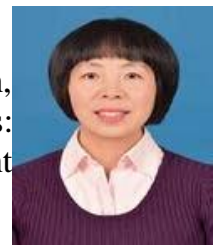

